\title{
COMPUTER ART \& OUTPUT THE IMPASSIVE LINE.
}

Professor Paul Coldwell

Chelsea College of Art \& Design

University of the Arts London

16 John Islip St

London

SW1P 4JU

p.coldwell@chelsea.arts.ac.uk

This paper considers the issue of digital output in the light of the author's early experience of observing plotter drawings at the Slade School of Art in the mid 1970's. The paper proceeds to discuss the author's own work in terms of a range of outputs and their implications in forming a relationship between old and new technologies. Other artists referenced in this paper include Michael Craig-Martin and Kathy Prendergast. The paper draws on research from the AHRC funded project, The Personalised Surface within Fine Art Digital Printmaking.

\section{THE IMPASSIVE LINE}

In Digital Culture, Charlie Gere argues that " the artist who has had the most profound influence on our current digital culture is the composer John Cage. Through his pioneering artistic practice in the 50's and 60's and through his influence on other practitioners and groups, he fostered interest in a set of concerns that would later become central to the development of digital media and digital art' [1]

Gere then goes on to describe the fact that Cage's early work didn't involve computers at all but suggests that in the 1950's Cage was 'responding to a similar set of issues and ideas to those that were beginning to be rehearsed in relation to computers.'

As a young artist I was excited by the possibilities of Cage's work well before I had any idea of its relationship to the computer. Ideas take time to filter through and sometimes longer for an artist to become conscious of the root of their ideas. This has certainly been the case in my own work in particular in relationship to the change from a language of drawing as an expression of an individual signature, through to a more impassive line, a line that seeks its quality from its clarity and detachment. Gere's assertion also suggests the way in which ideas lead technology and that in many cases, new technology can provide an artist with a solution to a problem already being tested through older technologies. But before going into more detail about my own work, I wanted to describe 


\section{CAT 2010 London Conference $\sim 3^{\text {rd }}$ February \\ Paul Coldwell}

the circumstances under which I first encountered the computer as a tool within art practice.

I was a postgraduate student in Printmaking at the Slade School of Art in the mid 1970's, The Slade at this time was composed of many different fractions, life drawing under the tutelage of Euan Uglow and Patrick George who perpetuated the Coldsteam approach of measurement and restraint, printmaking under dos Santos and Stanley Jones looked to Goya and Pirenasi and the School of Paris while the painting department under Malcolm Hughes was committed to an exploration of systems, Into this strange mix was also what was referred to as the experimental department, a hybrid space under Hughes, where the use of the computer within art was being explored.

Whilst there was limited interaction between the various departments, there was a sense throughout the Slade that drawing underpinned practice and along side this, a questioning of what drawing might be. In this respect John Cage and Marcel Duchamp were significant influences, providing evidence of an approach to art in which ideas took president over gesture and emotion and where the mark could be seen as a consequence of predetermined decisions.

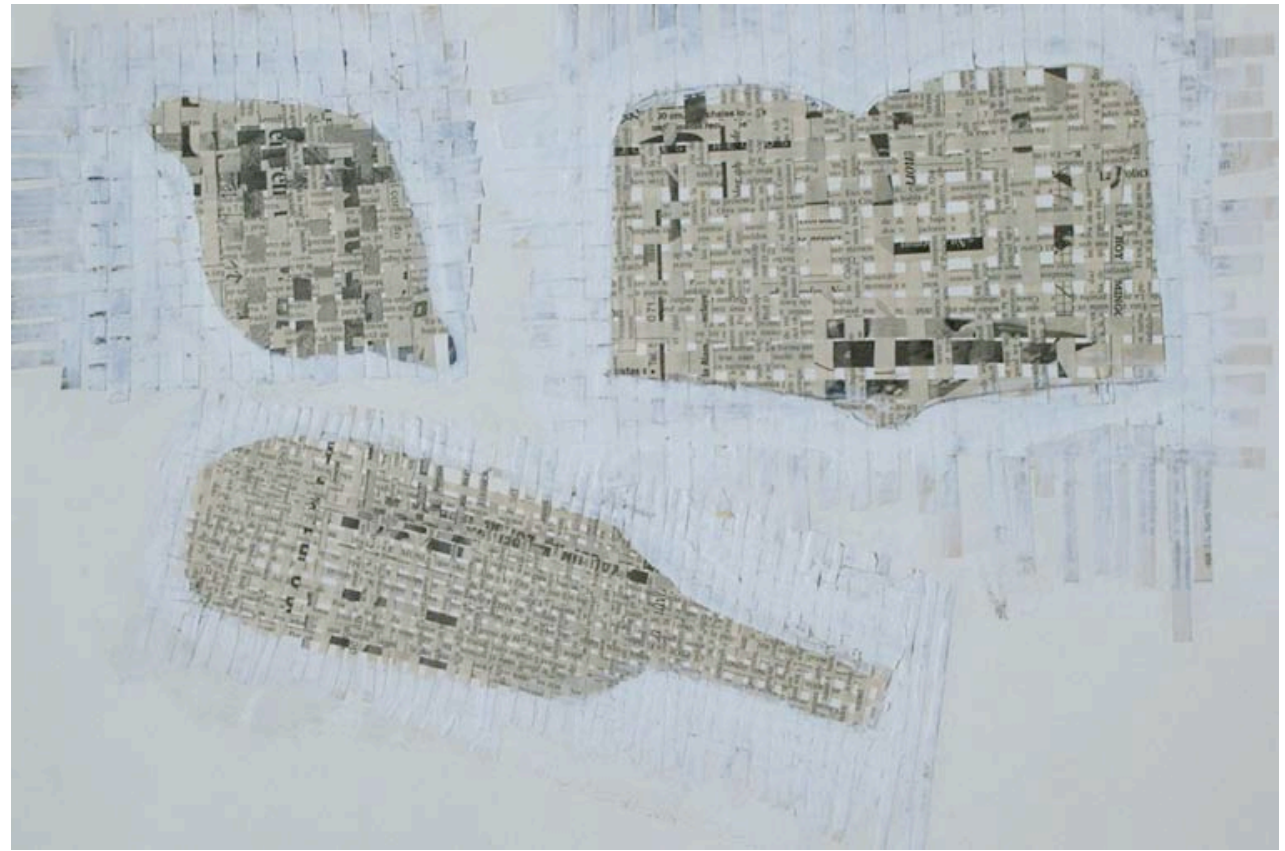

1. P.Coldwell -Drawing-mixed media on paper

While at the Slade, although not personally involved with the experimental department, I was aware of the work of Chris Briscoe, Julian Sullivan and Darrel Viner, and their attempts to get output from their computers. For the most part this took the form of printouts using a flatbed ink plotter. For me there were two distinct reasons against 
getting involved with this technology. Firstly that at that time a knowledge of programming was essential and secondly that it seem immensely time consuming and that drawings I naively felt could have been done in a few minutes with a ruler and pen, took sometimes days to output.

The plotter drawings were also challenging to me as a printmaker. It was unclear if these were to be seen as drawings or prints, either way they had the quality of office documents rather than fine art. They seemed far removed from the emphasis on handmade paper and rich physical qualities that as printmakers we took as pre requisites. However the then research assistant in printmaking, Chris Crabtree, himself well versed in programming had begun to be involved in the experimental department and was developing computer drawings that would then be realised through photo etching or lithography.

This early encounter, combined with other ideas 'in the air' has shaped my approach towards the computer, steering my work away from what I could describe as "painterly concerns' to ideas that were more centred on drawing. I was moving away from a gestural language towards a more objective approach and on reflection my thinking was being shaped and reformed by amongst other things this observation of the computer as a tool.

In printmaking there is a very natural separation between action and result. Working in intaglio for example there is the obvious mirror reversal of image as well as the fact that the etched line is drawn as a bright line in a dark ground which, when etched, becomes a black line against the white of the paper. Likewise in lithography and screen-print, where original marks are translated into ink on paper, its colour independent of the original drawing. So from this perspective, the idea of translation, from the image developed on computer screen to a physical output is part of the natural thinking within the discipline of printmaking. 


\section{CAT 2010 London Conference $\sim 3^{\text {rd }}$ February

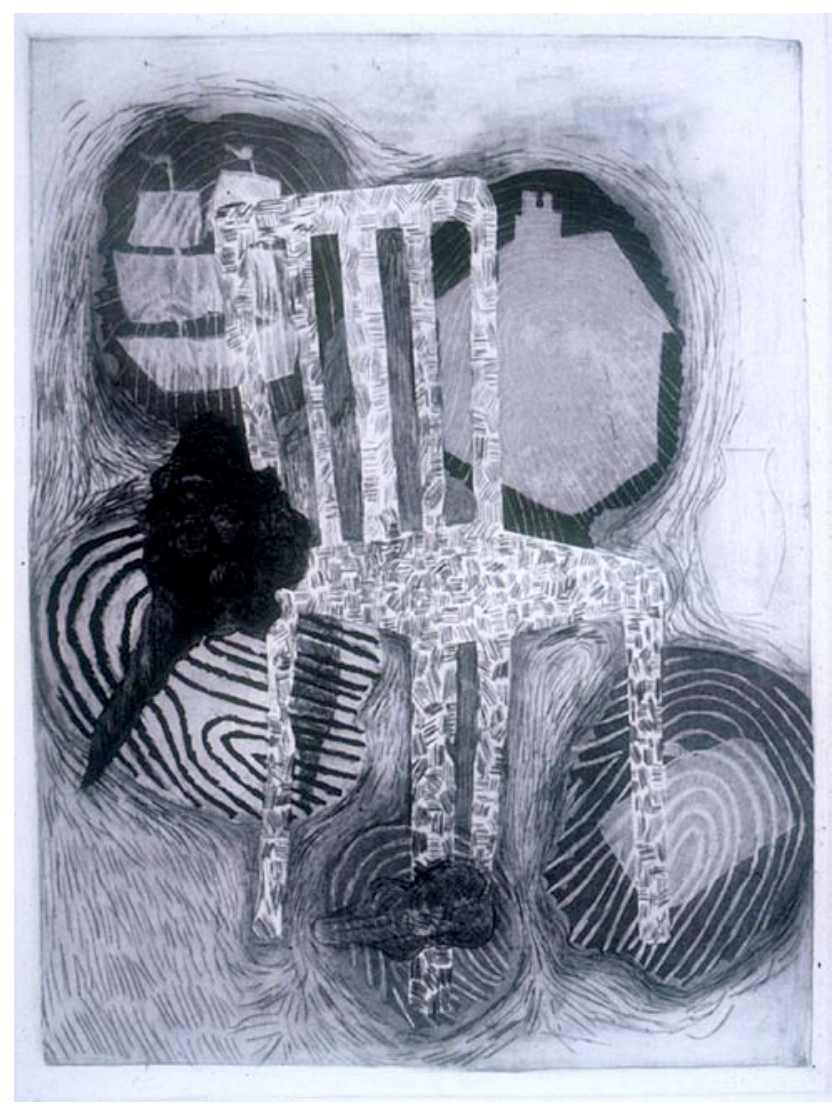

2.P.Coldwell -Chair, Etching \& Aquatint

Barbara Nierhoff_Wielk identifies this connection between printmaking and the computer, seeing is as both part of that history but also a radical departure.

'Is the computer then a new tool like pen and pencil in former times, or is computer graphics a new printing technique like lithography, for example, in the $19^{\text {th }} \mathrm{c}$, or serigraph in the mid $20^{\text {th }} \mathrm{c}$ ? It is far more than that- the computer may well also be a new tool, and computer graphics also a new printing technique, but it is first and foremost the expression of a new conception of an image'... even if plotter drawings look like hand drawings at first, they are nevertheless pictures that have been drawn neither by the hand of an artist, nor printed from an artist's hand made template. Instead, they have been calculated by a computer according to a specific programme and drawn by a plotter.'[2]

While it would be 20 years before I would begin to use the computer as part of my practice, I had begun to experiment with ways of creating a more detached line. I traced, reduced drawings through multiple photocopying, played with drawing tools to enlarge or reduce and used printmaking as an intentionally intermediary process. 


\section{CAT 2010 London Conference $\sim 3^{\text {rd }}$ February

In a recent conversation with Michael Craig-Martin at the V\&A, he spoke with great insight about his experience of discovering the computer. We had discussed how his recent work developed from his wall drawings from the Rowan Gallery in 1978 which were hand drawn, photographed, then projected onto walls and redrawn using tape.

' ... and suddenly I realised, cut and paste, that's what I had been doing with these drawings. So I scanned all the template drawings and got them in the computer. They were very crude pixalated images but it was like a dream come true, as if someone in heaven had thought, what does Michael need, he needs a computer that does cut and paste. And suddenly all those things I couldn't do before, I could do. I could suddenly make the drawings $1 \%$ or $200 \%$ bigger, I could flip them over, I could do anything with these images and I could see it instantly. I could save it, do another, it was as though I had spent ten to fifteen years waiting for the computer.' [3]

Craig-Martin confirms that view that ideas lead technology and certainly this was the case when I first began using the computer.

My memory of the early pioneers had fixed in my mind something about the space that I would explore when I came to making works through the computer myself. In those drawings they had explored a flat space personified by the flat bed plotter itself, a space in which lines can be directed to go up, down or across, a space referencing Paul Klee's maxim of taking a line for a walk. 


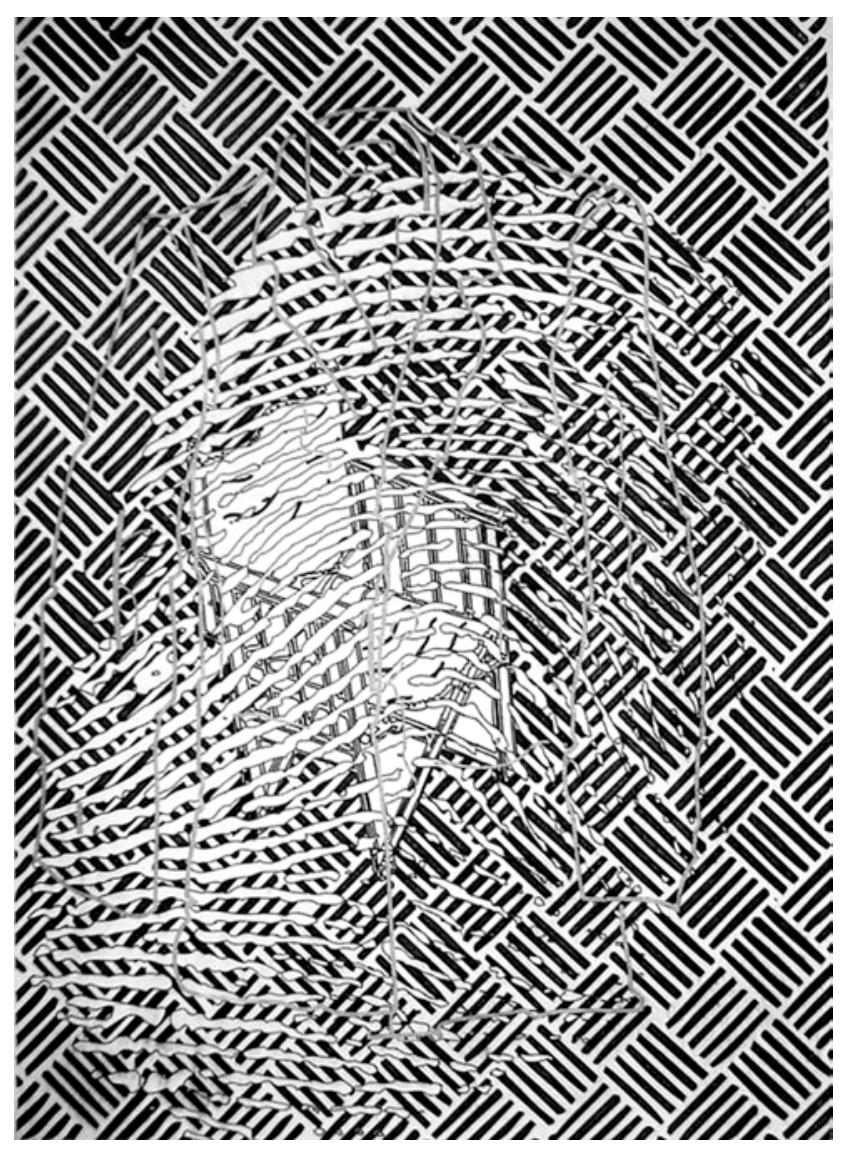

3. P.Coldwell- My Father's Coat. Etching from Digital File.

My first attempts with the computer were in 1995 when I was invited by Tristan Humphries to join a small research project between Camberwell College of Arts and Chelsea College of Art \& Design, which was looking at the potential of the computer in relationship to for printmaking.

Whilst by this stage, software such as illustrator and Photoshop enabled artists like myself with no programming skills to work independently with the computer, I was greatly helped by the assistance of George Whale, whose patience and troubleshooting proved invaluable. There were issues however that had to be taken into account. The choice of paper was limited, either a thin matt cartridge or else a high gloss for more photographic work and most importantly, the inks themselves were fugitive, being at that stage dye based. There was also considerable delay between action and result; there was a delay in drawing a line and seeing it manifested on screen and also there was the continuous requirement to save since the machine would regularly crash. Together these made me aware that working on the computer was a very different activity to simply drawing. It required planning, patience and I also began to understand that it might require a different way of working emotionally. 
These early works of mine where fully developed on screen and then transferred to photo etching. This enabled me to have the benefit of the fluidity of developing the drawing within the computer and then the use of my craft skills in realising them as finished works in print. I could etch each line according to its particular need and in some cases, etch the whole plate to a sufficient depth that I could print it as if it were relief. What I was particularly excited by was the fact that the final output didn't have to reveal the complexity of their making. Whereas in my previous prints, the etching plate for example would be a record of all my actions, using the computer I was able to edit out all the preparatory work. I could also redraw elements whilst still keeping the original as both a reference and alternative option. In addition I also became more aware of was the kind of space I wanted to deal with. I wasn't interested in trying to construct a deep space; I was interested in marks across the surface.

When drawing in the computer, I have always used the mouse as my preferred tool. This is to signal to myself that drawing in the computer has little resemblance to drawing with pencil or other drawing tools. I hold the mouse with my whole hand, and I draw by either sliding it across the mat or else, by clicking, fix points. This also reinforces the fact that the space I am dealing with is a flat space and whilst I use layers, I know that these are virtual rather than real.

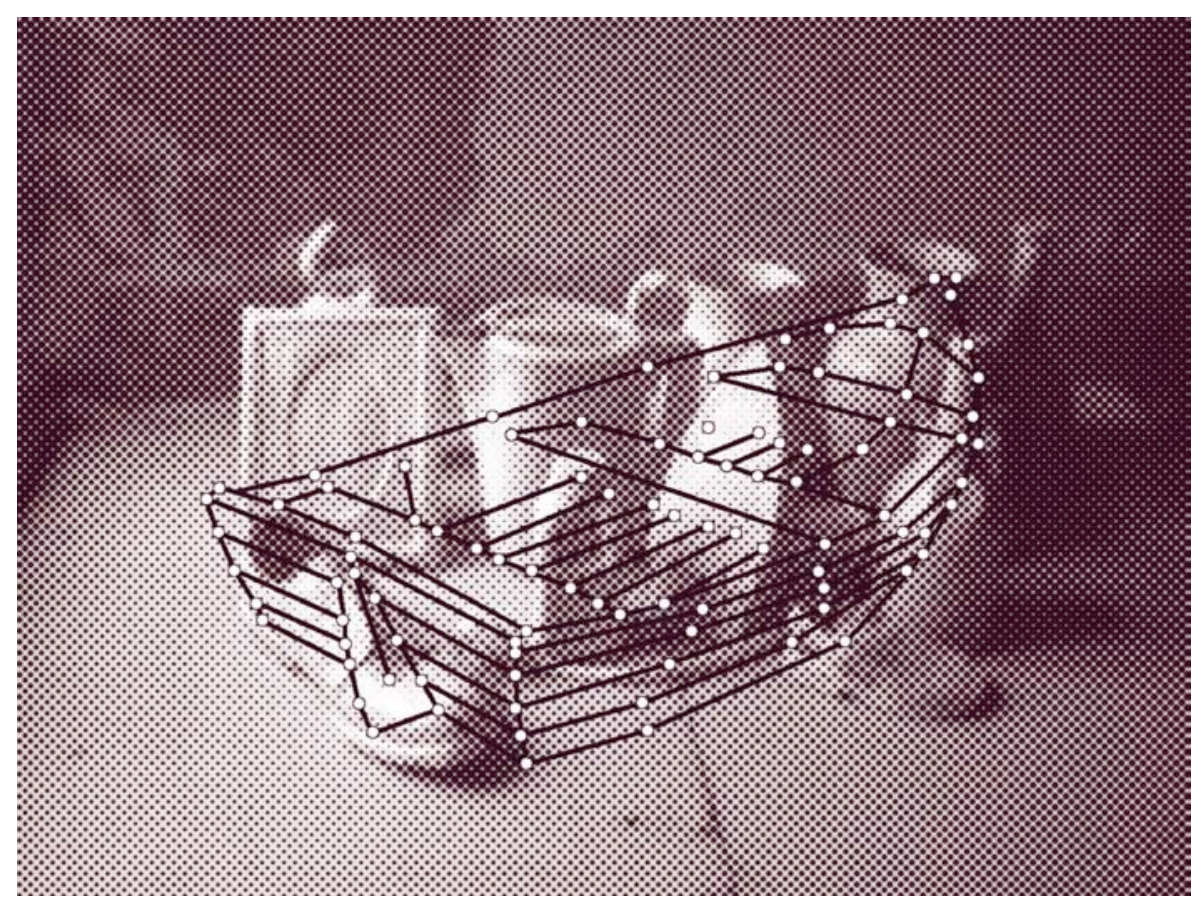

4. P.Coldwell- Constellations. Inkjet 
A further aspect for me in using the computer has been the rather obvious fact that drawing and photography can be brought into the same space. A photograph once imported, becomes malleable.

Digital reproduction makes manifest what we always knew about the suspect nature of photography's claim to objectivity, by promising to reunite photographic reproduction with painting"[4]

When I use the photograph in my work is to be seen as a graphic device. The image is invariably half toned, a reference to the means through which a photograph is transformed from chemical to graphic representation, but also so it is apparent that the information, like the drawing is to be read across the surface. This had led to works which play between the two languages of drawing and photography within a space where each is equally subject to change, the drawing literally linking points across the surface of the photograph. I have also in manner cases treated the photograph as a drawing, manipulating each half tone dot, enlarging or reducing, to literally redraw the photograph.

While for the early pioneers, the means of achieving output was somewhat limited; the contemporary artist is now presented with an almost infinite choice. There are perhaps two distinct categories, the first in which the image remains within the digital environment, i.e. the computer driving a plotter, printer or cutter to produce an image that has literally been untouched by human hand as in Tim Head's Dust Flowers (inkjets) or Marlene Oliver's digitally engraved acrylic Exhausted Figure 2007. This approach can also include works which are conceived specifically for the monitor or plasma screen as with Craig-Martin's Becoming 2003, where using bespoke software, a continually changing set of relationships is played out. The second category is where digital output is used to engage with older technologies for example in plate making or forming the positives for screen prints as with Julian Opie, Watching Suzanne 2006, (screen-print on acrylic sheets), or laser cutting the woodblocks as with Terry Winters, the blocks then printed using a conventional press. Increasingly there is an understanding that the digital does not have to operate within its own vacuum but can be seen within the wider context of printmaking. 


\section{CAT 2010 London Conference $\sim 3^{\text {rd }}$ February \\ Paul Coldwell}

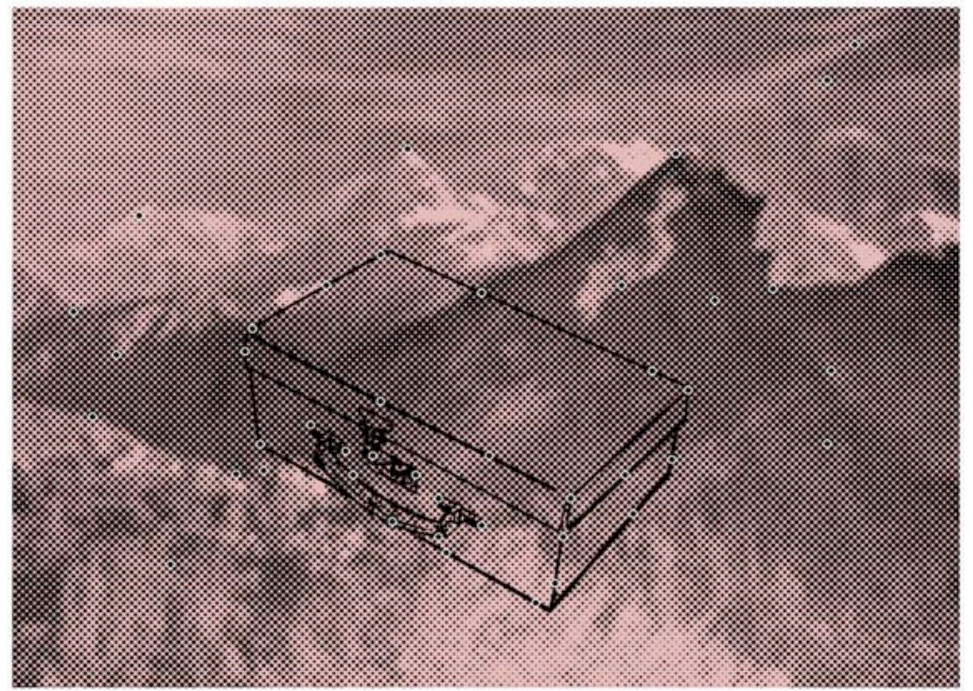

5.P.Coldwell-Sites of Memory:Suitcase. Screenprint

In terms of output, as mentioned my earlier digital work used photo etching as means to print out, and I have subsequently used lithography, screen-print as well as images conceived and executed through inkjet. In addition I have begum to combine inkjet with polymer plates and lino cut to introduce areas of relief printing to the inkjet image.

The inkjet print is now a far cry from the first four colour Encad prints. The new range of large format printers not only print to the highest photographic standard but also are also capable of outputting onto a range of substrates, from heavy fine art papers through to plastics and material. However there is uniformity, perfection about this technology that doesn't always sit with artist's intentions and needs. In a recent research project, The Personalised Surface within Fine Art Digital Printmaking, this question of output was addressed through artist's case studies and interviews.

One of the artists involved in the project was Kathy Prendergast, an artist who we first worked with in 1999. Then she developed, with the research assistant George Whale, the print Lost Map in which she took the data of a map of North America and stripped it of all its place names. Then she systematically reinstated all those names with the suffix lost placing them according to their coordinates. This was an intriguing project working on many levels, which while on one level utilises the computer as a tool for detached manipulation of data, on another level resulting in an artwork with great depths of emotional feeling. Prendergasts's map reveals an emotional seam within America's geography and history, places of loss and unfulfilled dreams. In addition, it reveals those places that are too small to be registered on a broad map of America, a reminder of the manner in which a continent is populated by individuals. This further connects to her own Irish background and that history of emigration in the search for a better life. Prendergast's sculpture work and drawing is characterised by an intense physical engagement, which here she substitutes for a manipulation of data. 


\section{CAT 2010 London Conference $\sim 3^{\text {rd }}$ February

PC It could seem from what you have said...that there could be a contradiction for you in using digital technology. You don't have the direct correlation between your hand and the mark.

KP Well I agree. It's a completely alien process for me, there's a distance there. The first project I did with this technology was Lost map and it could only be done through the technology. I looked up emotional place names and tried to hand draw the maps but it didn't work, so when you invited me to work with the project it was an opportunity to use this technology and I realised how important it could be for artists.

PC ... you digitally unraveling the surface of the map.

KP It was deleting, not drawing, an act of destruction removing all the other place names. It was the opposite of drawing.[5]

Working with her again, this time supported by Jonathan Kearney, she took a contour map of Mt Fuji and gradually interwove an image of cherry blossom, reinforcing the reference to Japanese ukoyo prints. Here her process was to output through inkjet, draw onto the proofs, scan, reprint, re draw until the image reached a conclusion. Here the output is both serving as proofing to give a physical evidence of the image on screen as well as a substrate to receive more drawing. Prendergast's drawing occurred both on screen and on paper, a continuous dialogue between virtual and real. 


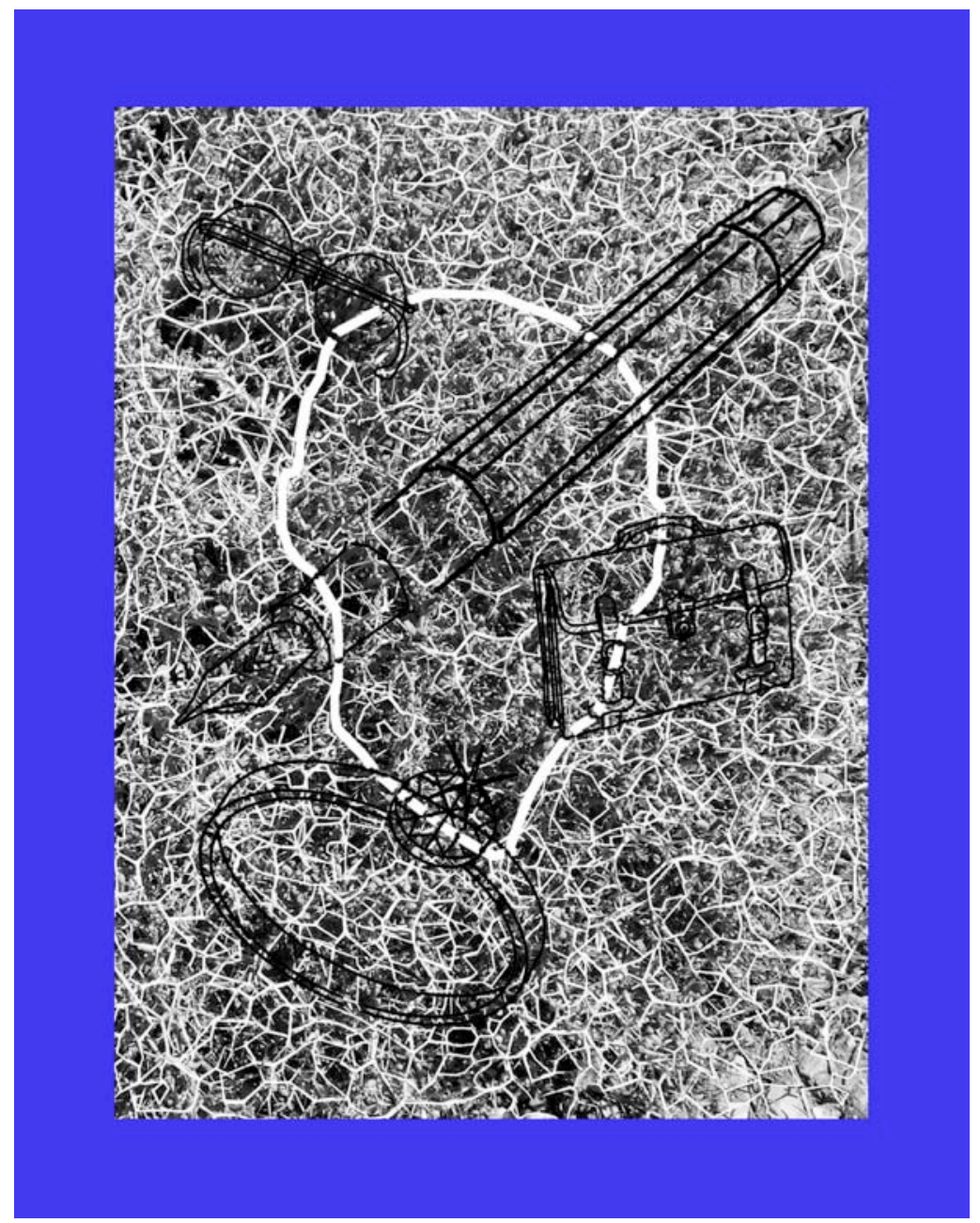

6. P.Coldwell-Untitled, Inkjet \& Linocut

This relationship between virtual and real offers exciting possibilities, especially in my view when this new technology is seen within a broader tradition of printmaking. New technology enables older technologies to be revisited and examined for untapped potential and as the hardware gets cheaper and more assessable, artists will have more opportunity to play. As a footnote, I am currently exploring ways of producing prints through laser cut, perhaps not so far away from the original plotter drawings that made such an impression on me in the mid 1970's. 
CAT 2010 London Conference $\sim 3^{\text {rd }}$ February

Paul Coldwell

\section{References}

[1] GERE, C: Digital Culture 2002, London, Reaktion Books p.77

[2] NIERHOFF-WIELK, B: Ex-machina-The encounter of computer and art. A look back. Breman, Deutscher Kunstverlag, P22

[3] CRAIG-MARTIN, M : In Paul Coldwell in Conversation with Michael CraigMartin, The Personalised Surface. New approaches to Digital Printmaking, 2009, London, Fade research, p87

[4] OWEN, W : Unsteady States. In Digital Prints ed Adam Lowe, 1997, London, Permaprint p 22

[5] KATHY PRENDERGAST in Conversation with Paul Coldwell. In The Personalised Surface. New approached to Digital Printmaking, CD, 2009, London, Fade Research. 